\title{
Bethany Klein: As heard on TV: Popular music in advertising. Surrey: Ashgate. 2009
}

\section{Nicolai Jørgensgaard Graakjær}

\author{
MedieKultur 2010, 48, 133-135
}

Published by SMID | Society of Media researchers In Denmark | www.smid.dk The online version of this text can be found open access at www.mediekultur.dk

Since the turn of the millennium, the Ashgate Popular and Folk Music Series has provided a number of important studies on popular music. Klein's contribution on pre-existing popular music in advertising is one of the most recent, and it examines a field of research on the periphery of traditional musicology. Thus, the subject of the book is important and the scope is wide-ranging. In addition to musicologists, media and communication researchers ought to be able to find something of interest as well.

Inspired by the following observation, "in marketing, and particularly in television commercials, popular music has become ubiquitous" (Klein, 2009, p. 1), Klein sets out to explain and discuss why pre-existing popular music in advertising has become ubiquitous and what the consequences are for music, the music industry, and for marketing.

Empirically, the examination is based on 29 in-depth interviews with respondents who all occupy positions with direct influence on the business of so-called music placement in TV commercials, be it music supervisors, advertising creatives, licensing managers or musicians. Accordingly, the perspective is producer oriented, and thereby the book offers insights into hitherto - for the outsider - rather murky processes of cultural production. However, as a consequence of the reliance on interviews, the insights are filtered by respondents' memories and possible self-presentations. Moreover, the focus is on the expression of beliefs and attitudes of the respondents at the expense of descriptions of actual procedures and practices. Klein is well aware of this possible limitation to the empirical material, and she reasonably suggests that participatory observation might have proved empirically validat- 
ing - Klein goes on to dismiss such an initiative by pointing to the risk of having to "...wait weeks or months before anything relevant to the use of popular music occurs" (p. 143).

While this is an intelligible dismissal, the quote suggests that popular music in commercials might not be that "ubiquitous" after all. Throughout the book (at least ten times), the extensive and increased use of popular music is postulated as a supposedly self-evident fact, but the absence of specific empirical validation becomes increasingly clear as the postulates mount. Indeed, the book identifies a considerable number of case studies - obviously inspired by the interviews: "Conversations often turned to high profiled cases of popular music in advertising" (p. 144) - but the reader is left wondering whether these examples are really representative of a widespread and/or rising phenomenon. Thus, the book would have gained more authority by providing the reader with a substantial discussion on the actual spreading of pre-existing popular music in commercials. Of course, large scale sample material would have been indicative of the prevalence of pre-existing popular music, but even a more systematic evaluation of previous literature on - and related to - the subject of interest might have been instructive in this respect. As a consequence of these exclusions, Klein's balanced discussions on dilemmas involved in music placement in commercials (most notably the dilemma of "artistic autonomy versus economical success") may seem not to bring much new to readers familiar with previous studies on, e.g., music placement in films and studies on the (ab)use of classical music in commercials.

What the book arguably lacks in theoretical systematisation and contextualisation it has in very fascinating case studies and hereunder colourful statements made by the cultural producers interviewed. Carefully described, the case studies are both illustrative and stimulating.

In chapter 2, issues of copyright are discussed, and the controversial use of the Beatles' Revolution in a commercial from 1987 for NIKE functions as a remarkable case. An impressive degree of detail and perspectives are offered concerning a subject matter that is notoriously complex with "...infinite combinations of publishing and master rights, involving any number of parties" (p. 26). The sections on the legal strife (and mudslinging) involving Michael Jackson versus Paul McCartney and Yoko Ono are both amusing and illuminating.

Chapter 3 discusses how the uses of pre-existing popular music in commercials occasionally have generated unexpected positive responses from both critics and fans. It seems that a decisive factor for this to occur is an ingenious (re)construction of the meaning potentials offered by the pre-existing music. However, Klein does not provide analytical exemplification of this phenomenon in much detail, and generally - throughout the book - case studies are not supplemented by text analysis of the commercials in question. Actually, the "music" of popular music seems never to come into view in the case studies, and while the lyrics of particular songs are repeatedly highlighted, the specific audiovisual construction of commercials (e.g., the specific extracts of the song and the detailed synchronisation of music to specific visual elements) is usually left undisclosed. Possibly, this makes the case studies immediately graspable for non-musicologists, but at least to musicologists the lack 
of references to analytical popular musicology can seem somewhat frustrating. This also holds true for the related chapters 5 and 6 , which deal with musical branding and transfer of musical meaning, respectively.

Chapter 4 offers an insightful mapping of changes in the business of promoting popular music. A central premise is pinpointed: "As changes in the radio and music industries have resulted in narrower opportunities for a narrowing range of artists, the advertising industry gladly stepped in to offer musicians and labels large sums of money and potential widespread exposure" (p. 60). Described by Klein as a "licensing orgy" (p. 59), the very successful (measured by albums sold) promotion of Moby's Play (1999) functions as the example par excellence: All 18 tracks were licensed to appear in commercials, films and as signatures for TV programmes. As previously implied, music placement is not something entirely new (the phenomena dates back to at least the 1950s), but perhaps what is new is that upcoming, unknown musicians and labels of today are routinely considering indirect promotion of music via commercials (the case of Moby also functions as an inspiration in this respect). On the face of it, the strategy is an all win-situation: artists gain indirect access to prime time commercial television and commercial radio airplay, manufactures (via commercial agencies) gain access to relatively inexpensive, possible cutting-edge music, and audiences are exposed to "creative" commercials. Judged by Klein's descriptions, it is customary practice for manufactures to pay for the use of music from upcoming, unknown artists, but perhaps the day will come, Klein ponders though-provokingly and a bit worried, when musicians and labels have to pay for exposure in commercials.

In any event, the distribution of popular music in advertising is an important field of research. Klein has made a significant and pioneering contribution when it comes to the production perspective related to television commercials in particular. Hopefully, the book can inspire further research into a field of cultural production, from which we have not yet heard it all.

Nicolai Jørgensgaard Graakjer Associate Professor, Ph.D. Department of Communication and Psychology University of Aalborg, Denmark nicolaig@hum.aau.dk 